Diterima : 7 September 2018

Disetujui : :9 Desember 2018

Dipublikasikan : 30 Januari 2019

\title{
KORELASI ANTARA KEMAMPUAN MEMBACA KRITIS DENGAN KEMAMPUAN MENULIS ARGUMENTASI SISWA KELAS VII A SMP NEGERI 9 KOTA BENGKULU
}

\author{
Vebbi Andra \\ IAIN Bengkulu, Bengkulu, Indonesia \\ Posel : vebbiandra@yahoo.com
}

\begin{abstract}
This research is a quantitative research that uses a correlational method. The population and sample in this study were all students of class VII A SMP Negeri 9 Kota Bengkulu in the 2016/2017 school year, which amounted to 30 students. The results showed that the existence of critical reading skills in the ability to write arguments is classified as very strong $(0,852)$, meaning that critical reading skills are very supportive of the ability to write arguments. Where the variable critical reading ability contributes to the variable ability to write arguments at 72,59\%, and also shows that $t$ count is greater than $t$ table or 8,623 > 1,701, meaning that there is a significant relationship between critical reading ability to the ability to write arguments.
\end{abstract}

Keywords: critical reading, argument writing, SMP

\begin{abstract}
Abstrak : Penelitian ini merupakan penelitian kuantitatif yang menggunakan metode korelasional. Populasi dan sampel dalam penelitian ini adalah seluruh siswa kelas VII A SMP Negeri 9 Kota Bengkulu pada tahun pelajaran 2016/2017, yang berjumlah 30 orang siswa. Hasil penelitian menunjukkan bahwa keberadaan kemampuan membaca kritis terhadap kemampuan menulis argumentasi tergolong adalah sangat kuat $(0,852)$, artinya kemampuan membaca kritis sangat mendukung terhadap keberadaan kemampuan menulis argumentasi. Di mana variabel kemampuan membaca kritis memberikan kontribusi terhadap variabel kemampuan menulis argumentasi sebesar 72,59\%, dan juga terlihat bahwa $t$ hitung lebih besar dari $\mathrm{t}$ tabel atau 8,623 >1,701, artinya ada hubungan yang signifikan antara kemampuan membaca kritis terhadap kemampuan menulis argumentasi..
\end{abstract}

Kata Kunci :membaca kritis, menulis argumentasi, SMP 


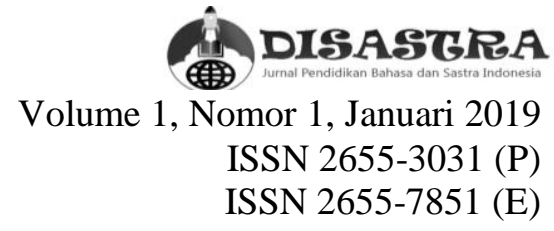

\section{Pendahuluan}

Berbahasa adalah aktivitas sosial, kegiatan berbahasa baru dapat terwujud apabila manusia terlibat di dalamnya. Pada saat berbahasa tentu saja melibatkan berbagai aspek, aspek-aspek di dalam berbahasa dikenal dengan keterampilan berbahasa. Keterampilan berbahasa dalam kurikulum di sekolah biasanya mencakup empat segi, yaitu: keterampilan menyimak, keterampilan berbicara, keterampilan membaca, dan keterampilan menulis. Keterampilan berbahasa ini antara satu dan lainnya sangatlah berhubungan erat, apalagi dalam usaha seseorang untuk dapat memperoleh kemampuan berbahasa (Tarigan, 1979:7).

Semakin terampil seseorang berbahasa semakin jelas dan cerah pula pikirannya. Oleh karena itu, pengajaran bahasa di sekolah dapat diarahkan pada kegiatan melatih keempat keterampilan berbahasa tersebut, yaitu: kegiatan dalam melatih keterampilan menyimak, berbicara, membaca, dan menulis. Keterampilan yang diajarkan tersebut merupakan keterampilan dasar. Pembinaan keterampilan dasar bahasa Indonesia bertujuan meningkatkan mutu pengajaran bahasa Indonesia sehingga penuturnya memiliki: 1) keterampilan berbahasa Indonesia, 2) pengetahuan yang baik tentang bahasa Indonesia, dan 3) sikap positif terhadap bahasa Indonesia termasuk sastra. Untuk itu, pengajaran terhadap bahasa Indonesia mutlak dilaksanakan di semua lembaga pendidikan, termasuk tingkat SMP (Sekolah Menengah Pertama).

Dari empat keterampilan yang ada, keterampilan membaca dan keterampilan menulis perlu mendapatkan perhatian yang lebih dari guru bahasa Indonesia. Hal ini dikarenakan kemampuan siswa khususnya pada tingkatan SMP (Sekolah Menengah Pertama) kelas VII A, pada kedua aspek tersebut terlihat masih jauh dari harapan. Perhatian khusus diperlukan karena jika siswa lemah dalam menggunakan dua keterampilan tersebut, maka siswa nantinya akan berhadapan pada masalah kesulitan dalam berbahasa, yang pada akhirnya akan memperhambat perkembangan siswa dalam proses berinteraksi terhadap masyarakat.

Penguasaan siswa terhadap keterampilan membaca dan keterampilan menulis dianggap masih lemah, tentu saja bukan karena tidak ada alasan yang jelas. Selain lemahnya kemampuan berbahasa siswa terhadap kedua aspek tersebut, serta juga dikarenakan kedua keterampilan tersebut memiliki ragam jenis yang bermacam-macam. Hal ini tentu saja menyebabkan kesulitan pada siswa kelas VII A pada jenjang SMP (Sekolah Menengah Pertama), yang notabennya baru memasuki suasana baru setelah menyelesaikan jenjang SD (Sekolah dasar).

Salah satu jenis kemampuan membaca yang dipelajari di tingkat SMP (Sekolah Menengah Pertama), yaitu kemampuan membaca kritis. Sedangkan pada tataran menulis, siswa di tingkat SMP (Sekolah Menengah Pertama) ditekankan harus memiliki kemampuan dalam bidang menulis argumentasi.

Melihat pentingnya kedua keterampilan itu, yakni kemampuan membaca kritis dan kemampuan menulis argumentasi. Maka dalam hal ini, penulis akan menekankan fokus penelitian terhadap kedua aspek tersebut, terutama dalam melihat korelasi antara kemampuan membaca kritis dengan kemampuan menulis argumentasi pada siswa kelas VII A SMP (Sekolah Menengah Pertama) Negeri 9 Kota Bengkulu tahun pelajaran 2016/2017.

Penelitian tentang hubungan antara kemampuan membaca kritis dengan kemampuan menulis argumentasi siswa kelas VII A SMP (Sekolah Menengah Pertama) Negeri 9 Kota Bengkulu pada tahun pelajaran 2016/2017, merupakan suatu hal yang sangat penting dan harus dilakukan. Penelitian ini sangat penting dikarenakan memiliki fokus kajian yang berbeda dari penelitian sebelumnya. Sedangkan kenapa penelitian ini 
harus dilakukan, itu disebabkan bahwa pada saat sekarang ini penguasaan terhadap kemampuan atau keterampilan berbahasa sangatlah berperan penting untuk meraih kesuksesan seseorang dalam kehidupnya di masyarakat.

Berdasarkan latar belakang masalah yang diuraikan di atas, maka permasalahan dalam penelitian ini dapat dirumuskan sebagai berikut, apakah terdapat hubungan antara kemampuan membaca kritis dengan kemampuan menulis argumentasi? Jika terdapat hubungan bagaimanakah bentuk hubungannya dan seberapa besar kekuatan hubungannya?

\section{Hakikat Kemampuan Menulis Argumentasi}

Keterampilan menulis yang dimiliki oleh seseorang bukanlah suatu proses yang otomatis didapat sejak lahir, melainkan diperoleh dengan cara belajar serta diperkuat dengan latihan yang cukup dan teratur. Menulis merupakan suatu kegiatan berbahasa yang bersifat ekspresif. Bersifat ekspresif artinya kita dituntut untuk dapat menyampaikan informasi atau pesan kepada orang lain dalam bentuk tulisan. Poerwadarminta (1984:628) menyatakan bahwa kemampuan mempunyai arti, yaitu berupa kesanggupan, kecakapan, dan kekuatan. Sedangkan menulis adalah kegiatan menurunkan atau melukiskan lambanglambang grafik yang menggambarkan suatu bahasa yang dipahami oleh seseorang, sehingga orang lain dapat membaca lambanglambang grafik tersebut kalau mereka memahami bahasa gambaran grafik tersebut (Tarigan dalam Suhartono, 2005:15).

Menurut Morsey (dalam Suhartono, 2005:14) bahwa menulis pada umumnya dipergunakan orang yang terpelajar dengan tujuan untuk mencatat rekaman, meyakinkan, melaporkan, memberitahukan, dan mempengaruhi dengan menguraikannya secara jelas dan teratur serta menggunakan kata-kata dan struktur kalimat. Bait dkk. (1987:12) menganggap menulis merupakan kegiatan mengungkapkan isi jiwa, pengalaman, dan penghayatan melalui bahasa tulis sebagai alatnya. Berdasarkan beberapa pendapat di atas, maka dapatlah disimpulkan bahwa kemampuan menulis adalah kecakapan seseorang dalam suatu kegiatan mengimplementasikan bahasa lisan menjadi bahasa tulis, bisa saja menyalin atau melahirkan pikiran atau perasaan seperti mengarang, membuat surat, menyusun laporan, dan sebagainya.

Salah satu jenis kegiatan menulis adalah menulis argumentasi. Argumentasi merupakan suatu bentuk retorika yang berusaha mempengaruhi sikap dan pendapat orang lain agar mereka percaya dan akhirnya bertindak sesuai dengan apa yang diinginkan oleh penulis atau pembicara (Keraf, 1982:3). Sejalan dengan hal tersebut, Suhartono (2005:20) berpendapat bahwa argumentasi merupakan karangan yang berusaha untuk meyakinkan atau mempengaruhi sikap dan pendapat pembaca agar mereka percaya dan akhirnya bertindak sesuai dengan apa yang diinginkan oleh penulis. Jadi, berdasarkan beberapa pendapat di atas, maka dapatlah disimpulkan bahwa argumentasi adalah merupakan suatu karangan yang berisi pendapat penulis agar pembaca dapat percaya dan mengikuti pandangannya tersebut.

Berdasarkan berbagai pengertian yang ada, maka dapatlah dipahami dan disimpulkan bahwa kemampuan menulis argumentasi adalah kecakapan seseorang dalam suatu kegiatan mengimplementasikan bahasa lisan menjadi bahasa tulis, di mana ia berusaha melahirkan pikiran, perasaan, dan pendapatnya yang bertujuan agar pembaca dapat percaya dan mengikuti pandangannya tersebut.

Dalam K-13 (Kurikulum 2013) pada jenjang SMP, kegiatan pembelajaran siswa ditekankan pada tiga aspek pokok, yaitu: a) perkembangan aspek kognitif, b) perkembangan aspek psikomotor, dan c) perkembangan aspek afektif (Depdiknas, 2006:3-5). Dalam hal ini fokus kegiatan pembelajaran menulis argumentasi, yaitu 
ditekankan pada kemampuan siswa untuk mengungkapkan pikiran, perasaan, dan pengalaman siswa melalui berbagai bentuk tulisan.

\section{Hakikat Kemampuan Membaca Kritis}

Kemampuan membaca yang baik menjadi syarat bagi setiap siswa dalam mencari dan menuntut ilmu pengetahuan di sekolah. Hal ini bukan lagi suatu tuntutan yang berlebihan mengingat pada saat ini keberadaan buku sudah semakin banyak, sejalan dengan pesatnya perkembangan ilmu pengetahuan dewasa ini. Keterampilan membaca menjadi syarat mutlak sebagai sesuatu yang harus dikuasai oleh siswa dengan baik, karena hanya dengan membaca siswa dapat memperoleh ilmu pengetahuan dan teknologi yang berkembang pada saat sekarang ini.

Salah satu jenis kemampuan dalam membaca, yaitu kemampuan membaca kritis. Dalam hal ini, pandangan tentang membaca kritis yang diberikan para ahli sangat beraneka ragam, masing-masing memberikan pengertian yang berbeda. Membaca kritis adalah suatu proses yang dilakukan seseorang untuk memperoleh pesan atau informasi melalui bahasa tulis, baik yang tampak tertulis maupun yang tersembunyi. Sejalan dengan hal tersebut, Nurhadi (1987:60) menyatakan bahwa membaca kritis adalah kemampuan pembaca mengolah bahan bacaan secara kritis untuk menemukan keseluruhan makna bacaan, baik makna yang tersurat maupun yang tersirat.

Menurut Albert (dalam Tarigan, 1979:12) membaca kritis adalah sejenis membaca yang dilakukan secara bijaksana, penuh tenggang hati, mendalam, evaluatif, serta analitis, dan bukan mencari kesalahan. Sedangkan kata kemampuan itu sendiri, mempunyai arti kesanggupan, kecakapan, dan kekuatan (Poerwadarminta, 1984:628). Berdasarkan beberapa pendapat yang ada, maka dapatlah disimpulkan bahwa kemampuan membaca kritis adalah kesanggupan seseorang dalam melakukan suatu proses pengolahan bacaan secara aktif yang dilakukan dengan tujuan memperoleh pemahaman yang bersifat menyeluruh tentang bacaan itu, baik terhadap keadaan, nilai, fungsi, dan dampak bacaan tersebut.

Pada jenjang SMP (Sekolah Menengah Pertama), pembelajaran terhadap kemampuan membaca kritis dalam K-13 (Kurikulum 2013) terfokus dalam hal: a) menemukan informasi faktual, b) menemukan ide pokok yang tersirat, c) menemukan suasana (mood), d) memprediksi dampak, e) membedakan realitas dan fantasi, f) menilai kelengkapan gagasan, g) membuat kerangka bahan bacaan, dan h) membuat kesimpulan. Di mana secara umum dalam hal penguasaan kemampuan membaca kritis, siswa sebenarnya diharapkan dapat memahami berbagai ragam teks bacaan yang diajarkan secara baik dan tepat.

Agar tujuan dari K-13 (Kurikulum 2013) dapat tercapai dengan baik maka kemampuan membaca kritis siswa harus dibina dengan baik pula, khususnya dalam hal:

Kemampuan scanning, yaitu kemampuan mengarahkan gerak mata dalam membaca dari kiri ke kanan pada tiap baris kalimat bacaan.

Kemampuan fixing, yaitu kemampuan memusatkan penglihatan pada baris-baris kalimat bacaan.

Kemampuan selecting, yaitu kemampuan memilih dari input grafis kuncikunci yang memperlancar memproses informasi.

Kemampuan predicting, yaitu kemampuan memprediksi makna input grafis dengan memanfaatkan kaidah kalimat (grammar) dan kepekaan makna dari proses decoding.

Kemampuan forming, yaitu kemampuan membentuk persepsi berdasarkan proses seleksi dan prediksi.

Kemampuan searching, yaitu kemampuan mengangkat dari ingatannya pengetahuan tentang bahasa (informasi fonologikal, sintaktikal, dan semantikal) dan 
pengalaman serta latar belakang konsepsikonsepsi yang telah dimilikinya.

Kemampuan tentative choosing, yaitu kemampuan memilih secara tentatif kuncikunci sintaktik dan semantik yang tepat dimanfaatkan.

Kemampuan testing-semantic and syntactic, yaitu kemampuan menguji apakah kunci-kunci semantik dan sintaktik yang diterapkanya dapat dipertahankan apa tidak.

Kemampuan testing-grapho-phonic, yaitu kemampuan menguji apakah kuncikunci grafo-fonik yang diterapkanya dapat dipertahankan apa tidak.

Kemampuan regressing, yaitu kemampuan meninjau kembali kesalahankesalahan yang mungkin dibuatnya dalam tahapan-tahapan sebelumnya, dan sekaligus membetulkannya.

Kemampuan decoding, yaitu kemampuan mengintegrasikan informasi makna yang telah diperolehnya dari tahapantahapan proses sebelumnya sehingga menghasilkan suatu pemahaman atau komprehensif sebagai tujuan akhir membaca.

Kegiatan membaca kritis dapat dilakukan dengan mudah dan baik oleh siswa selain karena faktor-faktor di atas, juga dipengaruhi oleh penguasaan atas modelmodel membaca. Oleh karena itu, penguasaan atas model-model membaca merupakan salah satu hal yang berperan penting dalam menunjang kemampuan membaca kritis. Berikut ini ialah beberapa model membaca yang berperan dalam membaca kritis, yaitu: a) Model Membaca Bawah Atas (MMBA), b) Model Membaca Atas Bawah (MMAB), c) Model Membaca Timbal Balik (MMTB), d) model membaca SQ3R, e) model membaca SQ4R, f) model membaca POINT, dan g) model membaca PQRST.

Hipotesis penelitian ini adalah terdapat hubungan positif antara kemampuan membaca kritis dengan kemampuan menulis argumentasi. Artinya, makin baik kemampuan membaca kritis siswa, maka makin baik pula kemampuan menulis argumentasinya.

\section{Metode Penelitian}

Penelitian ini menggunakan metode korelasional. Hal ini sejalan dengan pendapat Margono (2005:9) bahwa korelasional adalah suatu metode yang bertujuan untuk melihat hubungan antara dua gejala atau lebih. Di dalam penelitian pendidikan, metode korelasional cendrung digunakan dalam penelitian kuantitatif. Menurut Margono (2005:35) kuantitatif merupakan suatu bentuk penelitian yang lebih menekankan pada indeks-indeks dan pengukuran secara empiris.

Oleh karena itu, dapatlah dipahami bahwa metode korelasional tidak bisa dilepaskan dari penelitian kuantitatif, terutama dalam mengumpulkan dan mengukur data secara baik. Dengan menggunakan metode korelasional pada penelitian kuantitatif, diharapkan nantinya dapat memperoleh pemahaman mendalam terhadap penghitungan statistik yang cermat, mengenai hubungan antara kemampuan membaca kritis dengan kemampuan menulis argumentasi siswa.

Populasi dalam penelitian ini adalah seluruh siswa kelas VII A SMP Negeri 9 Kota Bengkulu pada tahun pelajaran 2016/2017, yang berjumlah 30 orang siswa. Sedangkan sampel penelitiannya adalah juga berjumlah 30 orang siswa, dengan alasan apabila subjek penelitian kurang dari 100, maka subjek tersebut diambil semuanya sehingga bentuk penelitiannya ialah merupakan penelitian populasi (Riduwan, 2009:70)

\section{Hasil dan Pembahasa}

\section{Deskripsi Data Penelitian}

\begin{tabular}{|c|l|c|c|}
\hline $\begin{array}{c}\text { No } \\
\cdot\end{array}$ & \multicolumn{1}{|c|}{ Nama Siswa } & X & Y \\
\hline 1 & Aryo Nugroho & 70 & 85 \\
\hline 2 & Andre Kurniawan & 65 & 70 \\
\hline
\end{tabular}


Volume 1, Nomor 1, Januari 2019

ISSN 2655-3031 (P)

ISSN 2655-7851 (E)

\begin{tabular}{|c|c|c|c|}
\hline 3 & Alif Risko A. & 70 & 85 \\
\hline 4 & Agustian Syah P. & 60 & 70 \\
\hline 5 & $\begin{array}{ll}\text { Bintang } & \text { Septri } \\
\text { Bidari } & \\
\end{array}$ & 75 & 80 \\
\hline 6 & $\begin{array}{ll}\text { Dwi } & \text { Sapta } \\
\text { Sanarsih } & \\
\end{array}$ & 65 & 70 \\
\hline 7 & Diola Atha Fika & 70 & 85 \\
\hline 8 & $\begin{array}{l}\text { Een Repani Elsya } \\
\text { S. }\end{array}$ & 65 & 85 \\
\hline 9 & Eric Maulana & 70 & 80 \\
\hline 10 & Eko Candra S. & 60 & 75 \\
\hline 11 & Feby Aprilia S. & 85 & 90 \\
\hline 12 & Fadhila Nur F. & 80 & 85 \\
\hline 13 & M. Wisnu Saputra & 60 & 75 \\
\hline 14 & $\begin{array}{ll}\text { Marisa } & \text { Rahma } \\
\text { Padila } & \\
\end{array}$ & 70 & 75 \\
\hline 15 & Meta Riana & 65 & 70 \\
\hline 16 & M. Alip P. Z. & 70 & 75 \\
\hline 17 & $\begin{array}{l}\text { M. Yudistira } \\
\text { Bintang P. }\end{array}$ & 60 & 70 \\
\hline 18 & M. Chairawan & 65 & 75 \\
\hline 19 & Mayandra & 75 & 80 \\
\hline 20 & $\begin{array}{l}\text { Nindhiya Ainin } \\
\text { Dita }\end{array}$ & 80 & 85 \\
\hline 21 & Rano Putra & 85 & 90 \\
\hline 22 & Sartika Aprilia & 85 & 95 \\
\hline 23 & Syahrul Ramadhan & 65 & 75 \\
\hline 24 & Shindya & 70 & 90 \\
\hline 25 & Syahkira A. & 75 & 80 \\
\hline 26 & Salsa Billah & 85 & 90 \\
\hline 27 & Tamara & 90 & 95 \\
\hline 28 & $\begin{array}{l}\text { Welvi } \\
\text { Reftalobi }\end{array}$ & 60 & 75 \\
\hline 29 & Zelvia Putri & 70 & 85 \\
\hline 30 & Zainal Arif & 95 & 99 \\
\hline
\end{tabular}

\section{Deskripsi Data Kemampuan Membaca Kritis (X)}

\begin{tabular}{|c|l|c|}
\hline No. & \multicolumn{1}{|c|}{ Nama Siswa } & X \\
\hline 1 & Aryo Nugroho & 70 \\
\hline 2 & Andre Kurniawan & 65 \\
\hline 3 & Alif Risko A. & 70 \\
\hline 4 & Agustian Syah P. & 60 \\
\hline 5 & Bintang Septri Bidari & 75 \\
\hline 6 & Dwi Sapta Sanarsih & 65 \\
\hline 7 & Diola Atha Fika & 70 \\
\hline 8 & Een Repani Elsya S. & 65 \\
\hline 9 & Eric Maulana & 70 \\
\hline
\end{tabular}

\begin{tabular}{|l|l|c|}
\hline 10 & Eko Candra S. & 60 \\
\hline 11 & Feby Aprilia S. & 85 \\
\hline 12 & Fadhila Nur F. & 80 \\
\hline 13 & M. Wisnu Saputra & 60 \\
\hline 14 & Marisa Rahma Padila & 70 \\
\hline 15 & Meta Riana & 65 \\
\hline 16 & M. Alip P. Z. & 70 \\
\hline 17 & M. Yudistira Bintang P. & 60 \\
\hline 18 & M. Chairawan & 65 \\
\hline 19 & Mayandra & 75 \\
\hline 20 & Nindhiya Ainin Dita & 80 \\
\hline 21 & Rano Putra & 85 \\
\hline 22 & Sartika Aprilia & 85 \\
\hline 23 & Syahrul Ramadhan & 65 \\
\hline 24 & Shindya & 70 \\
\hline 25 & Syahkira A. & 75 \\
\hline 26 & Salsa Billah & 85 \\
\hline 27 & Tamara & 90 \\
\hline 28 & Welvi Dwi Reftalobi & 60 \\
\hline 29 & Zelvia Putri & 70 \\
\hline 30 & Zainal Arif & 95 \\
\hline
\end{tabular}

a. Skor Terbesar dan Terkecil

Skor terbesar $=95$

Skor terkecil $=60$

b. Nilai Rentangan (R)

$\mathrm{R}=$ Skor terbesar - Skor terkecil

$\mathrm{R}=95-60=35$

c. Banyaknya Kelas (BK)

$\mathrm{BK}=1+3,3 \log \mathrm{n}$ (Rumus Sturgess)

$\mathrm{BK}=1+3,3(30)$

$\mathrm{BK}=1+3,3(1,48)$

$\mathrm{BK}=1+4,884$

$\mathrm{BK}=5,884=6$ (dibulatkan)

d. Nilai Panjang Kelas (i)

$i=$ Error! Reference source not found.

$i=$ Error! Reference source not found.

$i=5,833=6$ (dibulatkan)

e. Tabulasi Tabel Penolong

Distribusi Frekuensi Variabel Kemampuan

Membaca Kritis (X)

\begin{tabular}{|c|c|c|c|c|c|c|}
\hline $\begin{array}{c}\mathbf{N} \\
\mathbf{o}\end{array}$ & $\begin{array}{c}\text { Kelas } \\
\text { Interval }\end{array}$ & $\mathbf{f}$ & $\begin{array}{c}\text { Nilai } \\
\text { Tengah } \\
\left(\mathbf{X}_{\mathbf{i}}\right)\end{array}$ & $\mathbf{X}_{\mathbf{i}}^{\mathbf{2}}$ & $\mathbf{f . \mathbf { X } _ { \mathbf { i } }}$ & $\mathbf{f . X}_{\mathbf{i}}^{\mathbf{2}}$ \\
\hline 1 & $60-65$ & 11 & 62,5 & $3.906,25$ & 687,5 & $42.968,75$ \\
\hline
\end{tabular}


Volume 1, Nomor 1, Januari 2019

ISSN 2655-3031 (P)

ISSN 2655-7851 (E)

\begin{tabular}{|r|c|c|c|r|r|r|}
\hline 2 & $66-71$ & 8 & 68,5 & $4.692,25$ & 548 & 37.538 \\
\hline 3 & $72-77$ & 3 & 74,5 & $5.550,25$ & 223,5 & $16.650,75$ \\
\hline 4 & $78-83$ & 2 & 80,5 & $6.480,25$ & 161 & $12.960,5$ \\
\hline 5 & $84-89$ & 4 & 86,5 & $7.482,25$ & 346 & 29.929 \\
\hline 6 & $90-95$ & 2 & 92,5 & $8.556,25$ & 185 & $17.112,5$ \\
\hline & Jumlah & $\mathbf{3 0}$ & & & $\begin{array}{l}\boldsymbol{\Sigma} \mathbf{f} \mathbf{X}_{\mathbf{i}} \\
\mathbf{2}\end{array}$ & $\begin{array}{l}\boldsymbol{\Sigma} \mathbf{f} \mathbf{X}_{\mathbf{i}}^{\mathbf{2}}= \\
\mathbf{1 5 7 . 1 5 9 , 5}\end{array}$ \\
\hline
\end{tabular}

\begin{tabular}{|l|l|c|}
\hline 14 & Marisa Rahma Padila & 75 \\
\hline 15 & Meta Riana & 70 \\
\hline 16 & M. Alip P. Z. & 75 \\
\hline 17 & M. Yudistira Bintang P. & 70 \\
\hline 18 & M. Chairawan & 75 \\
\hline 19 & Mayandra & 80 \\
\hline 20 & Nindhiya Ainin Dita & 85 \\
\hline 21 & Rano Putra & 90 \\
\hline 22 & Sartika Aprilia & 95 \\
\hline 23 & Syahrul Ramadhan & 75 \\
\hline 24 & Shindya & 90 \\
\hline 25 & Syahkira A. & 80 \\
\hline 26 & Salsa Billah & 90 \\
\hline 27 & Tamara & 95 \\
\hline 28 & Welvi Dwi Reftalobi & 75 \\
\hline 29 & Zelvia Putri & 85 \\
\hline 30 & Zainal Arif & 99 \\
\hline
\end{tabular}

Error! Reference source not found. =

a. Skor Terbesar dan Terkecil

Skor terbesar $=99$

Skor terkecil $=70$

71,7

g. Simpangan Baku (Standard Deviasi)

$\mathrm{s}=$ Error! Reference source not found.

$\mathrm{s}=$ Error! Reference source not found.

$\mathrm{s}=$ Error! Reference source not found.

$\mathrm{s}=$ Error! Reference source not found.

$\mathrm{s}=10,06$

Gambaran Data Kemampuan Menulis

Argumentasi (Y)

\begin{tabular}{|c|l|c|}
\hline No. & \multicolumn{1}{|c|}{ Nama Siswa } & Y \\
\hline & & \\
\hline 1 & Aryo Nugroho & 85 \\
\hline 2 & Andre Kurniawan & 70 \\
\hline 3 & Alif Risko A. & 85 \\
\hline 4 & Agustian Syah P. & 70 \\
\hline 5 & Bintang Septri Bidari & 80 \\
\hline 6 & Dwi Sapta Sanarsih & 70 \\
\hline 7 & Diola Atha Fika & 85 \\
\hline 8 & Een Repani Elsya S. & 85 \\
\hline 9 & Eric Maulana & 80 \\
\hline 10 & Eko Candra S. & 75 \\
\hline 11 & Feby Aprilia S. & 90 \\
\hline 12 & Fadhila Nur F. & 85 \\
\hline 13 & M. Wisnu Saputra & 75 \\
\hline
\end{tabular}

b. Nilai Rentangan (R)

$\mathrm{R}=$ Skor terbesar - Skor terkecil

$\mathrm{R}=99-70=29$

c. Banyaknya Kelas (BK)

$\mathrm{BK}=1+3,3 \log \mathrm{n}$ (Rumus Sturgess)

$\mathrm{BK}=1+3,3(30)$

$\mathrm{BK}=1+3,3(1,48)$

$\mathrm{BK}=1+4,884$

$\mathrm{BK}=5,884=6$ (dibulatkan)

d. Nilai Panjang Kelas (i)

$i=$ Error! Reference source not found.

$i=$ Error! Reference source not found.

$i=4,833=5$ (dibulatkan)

e. Tabulasi Tabel Penolong

Distribusi Frekuensi Variabel

Kemampuan Menulis Argumentasi (Y)

\begin{tabular}{|c|c|c|c|c|c|c|}
\hline No & $\begin{array}{c}\text { Kelas } \\
\text { Interval }\end{array}$ & $\mathbf{f}$ & $\begin{array}{c}\text { Nilai } \\
\text { Tengah } \\
\left(\mathbf{X}_{\mathbf{i}}\right)\end{array}$ & $\mathbf{X}_{\mathbf{i}}{ }^{\mathbf{2}}$ & $\mathbf{f . \mathbf { X } _ { \mathbf { i } }}$ & $\mathbf{f . X}_{\mathbf{i}}{ }^{\mathbf{2}}$ \\
\hline 1 & $70-75$ & 12 & 72,5 & $5.256,25$ & 870 & 63.075 \\
\hline 2 & $76-81$ & 4 & 78,5 & $6.162,25$ & 314 & 24.649 \\
\hline 3 & $82-87$ & 7 & 84,5 & $7.140,25$ & 591, & $49.981,75$ \\
& & & & & 5 & \\
\hline 4 & $88-93$ & 4 & 90,5 & $8.190,25$ & 362 & 32.761 \\
\hline 5 & $94-99$ & 3 & 96,5 & $9.312,25$ & 289, & $27.936,75$ \\
\hline
\end{tabular}


Volume 1, Nomor 1, Januari 2019

ISSN 2655-3031 (P)

ISSN 2655-7851 (E)

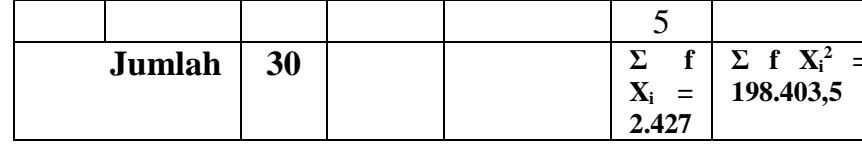

f. Rata-Rata (Mean)

Error! Reference source not found. = Error! Reference source not found.

Error! Reference source not found. = Error! Reference source not found.

Error! Reference source not found. = 80,9

g. Simpangan Baku (Standard Deviasi) $\mathrm{s}=$ Error! Reference source not found

$\mathrm{s}=$ Error! Reference source not found.

$\mathrm{s}=$ Error! Reference source not found.

$\mathrm{s}=$ Error! Reference source not found.

$\mathrm{s}=8,43$

Hubungan antara Kemampuan Membaca Kritis (X) dengan Kemampuan Menulis Argumentasi (Y)

a. Ha dan Ho dalam Bentuk Kalimat

Ha: Ada hubungan yang signifikan antara kemampuan membaca kritis (X) dengan kemampuan menulis $\operatorname{argumentasi}(\mathrm{Y})$

Ho: Tidak ada hubungan yang signifikan antara kemampuan membaca kritis (X) dengan kemampuan menulis $\operatorname{argumentasi}(\mathrm{Y})$

b. Ha dan Ho dalam Bentuk Statistik

Ha: $r \neq 0$

Ho: $r=0$

C. Tabel Penolong Menghitung Korelasi PPM

\begin{tabular}{|c|l|c|c|c|c|c|}
\hline No & Nama Siswa & $\mathbf{X}$ & $\mathbf{Y}$ & $\mathbf{X}^{\mathbf{2}}$ & $\mathbf{Y}^{\mathbf{2}}$ & $\mathbf{X Y}$ \\
\hline 1 & $\begin{array}{l}\text { Aryo } \\
\text { Nugroho }\end{array}$ & 70 & 85 & 4.900 & 7.225 & 5.950 \\
\hline 2 & $\begin{array}{l}\text { Andre } \\
\text { Kurniawan }\end{array}$ & 65 & 70 & 4.225 & 4.900 & 4.550 \\
\hline 3 & Alif Risko A. & 70 & 85 & 4.900 & 7.225 & 5.950 \\
\hline 4 & $\begin{array}{l}\text { Agustian } \\
\text { Syah P. }\end{array}$ & 60 & 70 & 3.600 & 4.900 & 4.200 \\
\hline 5 & $\begin{array}{l}\text { Bintang } \\
\text { Septri Bidari }\end{array}$ & 75 & 80 & 5.625 & 6.400 & 6.000 \\
\hline 6 & Dwi Sapta & 65 & 70 & 4.225 & 4.900 & 4.550 \\
\hline
\end{tabular}

\begin{tabular}{|c|c|c|c|c|c|c|}
\hline & Sanarsih & & & & & \\
\hline 7 & $\begin{array}{ll}\text { Diola } & \text { Atha } \\
\text { Fika } & \\
\end{array}$ & 70 & 85 & 4.900 & 7.225 & 5.950 \\
\hline 8 & $\begin{array}{l}\text { Een Repani } \\
\text { Elsya S. }\end{array}$ & 65 & 85 & 4.225 & 7.225 & 5.525 \\
\hline 9 & Eric Maulana & 70 & 80 & 4.900 & 6.400 & 5.600 \\
\hline 10 & $\begin{array}{l}\text { Eko Candra } \\
\text { S. }\end{array}$ & 60 & 75 & 3.600 & 5.625 & 4.500 \\
\hline 11 & $\begin{array}{l}\text { Feby Aprilia } \\
\text { S. }\end{array}$ & 85 & 90 & 7.225 & 8.100 & 7.650 \\
\hline 12 & $\begin{array}{ll}\text { Fadhila Nur } \\
\text { F. }\end{array}$ & 80 & 85 & 6.400 & 7.225 & 6.800 \\
\hline 13 & $\begin{array}{l}\text { M. Wisnu } \\
\text { Saputra }\end{array}$ & 60 & 75 & 3.600 & 5.625 & 4.500 \\
\hline 14 & $\begin{array}{l}\text { Marisa } \\
\text { Rahma Padila }\end{array}$ & 70 & 75 & 4.900 & 5.625 & 5.250 \\
\hline 15 & Meta Riana & 65 & 70 & 4.225 & 4.900 & 4.550 \\
\hline 16 & M. Alip P. Z. & 70 & 75 & 4.900 & 5.625 & 5.250 \\
\hline 17 & $\begin{array}{l}\text { M. Yudistira } \\
\text { Bintang P. }\end{array}$ & 60 & 70 & 3.600 & 4.900 & 4.200 \\
\hline 18 & $\begin{array}{l}\text { M. } \\
\text { Chairawan }\end{array}$ & 65 & 75 & 4.225 & 5.625 & 4.875 \\
\hline 19 & Mayandra & 75 & 80 & 5.625 & 6.400 & 6.000 \\
\hline 20 & $\begin{array}{l}\text { Nindhiya } \\
\text { Ainin Dita }\end{array}$ & 80 & 85 & 6.400 & 7.225 & 6.800 \\
\hline 21 & Rano Putra & 85 & 90 & 7.225 & 8.100 & 7.650 \\
\hline 22 & $\begin{array}{l}\text { Sartika } \\
\text { Aprilia }\end{array}$ & 85 & 95 & 7.225 & 9.025 & 8.075 \\
\hline 23 & $\begin{array}{l}\text { Syahrul } \\
\text { Ramadhan }\end{array}$ & 65 & 75 & 4.225 & 5.625 & 4.875 \\
\hline 24 & Shindya & 70 & 90 & 4.900 & 8.100 & 6.300 \\
\hline 25 & Syahkira A. & 75 & 80 & 5.625 & 6.400 & 6.000 \\
\hline 26 & Salsa Billah & 85 & 90 & 7.225 & 8.100 & 7.650 \\
\hline 27 & Tamara & 90 & 95 & 8.100 & 9.025 & 8.550 \\
\hline 28 & $\begin{array}{l}\text { Welvi Dwi } \\
\text { Reftalobi }\end{array}$ & 60 & 75 & 3.600 & 5.625 & 4.500 \\
\hline 29 & Zelvia Putri & 70 & 85 & 4.900 & 7.225 & 5.950 \\
\hline 30 & Zainal Arif & 95 & 99 & 9.025 & 9.801 & 9.405 \\
\hline & $\begin{array}{l}\text { Statistik } \\
\text { Jumlah }\end{array}$ & $\frac{\Sigma X}{2.160}$ & $\frac{\Sigma \mathbf{Y}}{2.439}$ & $\frac{\Sigma X^{2}}{158.250}$ & $\frac{\Sigma Y^{2}}{200.301}$ & $\frac{\Sigma X Y}{177.605}$ \\
\hline
\end{tabular}

d. $\quad \mathrm{r}$ hitung dengan Memasukkan Angka Statistik Tabel Penolong

$r_{X Y}$ Error! Reference source not found.

$r_{X Y}$ Error! Reference source not found.

$r_{X Y}$ Error! Reference source not found. $r_{X Y}$

Error! Reference source not found.

$r_{X Y}$ Error! Reference source not found. 0,852

(sangat kuat)

Interpretasi Koefisien Korelasi Nilai r

\begin{tabular}{|c|c|}
\hline $\begin{array}{c}\text { Interval } \\
\text { Koefisien }\end{array}$ & Tingkat Hubungan \\
\hline
\end{tabular}




\begin{tabular}{|c|c|}
\hline $0,800-1,000$ & Sangat Kuat \\
\hline $0,600-0,799$ & Kuat \\
\hline $0,400-0,599$ & Cukup Kuat \\
\hline $0,200-0,399$ & Rendah \\
\hline $0,000-0,199$ & Sangat Rendah \\
\hline
\end{tabular}

Besarnya Sumbangan (Kontribusi) Variabel $\mathrm{X}$ terhadap Variabel $\mathrm{Y}$

$$
\begin{aligned}
& \mathrm{KP}=\mathrm{r} 2 \times 100 \% \\
& \mathrm{KP}=0,8522 \times 100 \% \\
& \mathrm{KP}=72,59 \%
\end{aligned}
$$

Artinya variabel kemampuan membaca kritis memberikan kontribusi terhadap kemampuan menulis argumentasi sebesar $72,59 \%$ dan sisanya $27,41 \%$ ditentukan oleh variabel lain. Besaran Hubungan antara Kemampuan Membaca Kritis (X) dengan Kemampuan Menulis Argumentasi (Y)

$$
\begin{aligned}
& t_{\text {hitung }}=\frac{r \sqrt{n-2}}{\sqrt{1-r^{2}}} \\
& t_{\text {hitung }}=\frac{0,852 \sqrt{30-2}}{\sqrt{1-0,852^{2}}} \\
& t_{\text {hitung }}=\frac{4,51}{0,523} \\
& t_{\text {hitung }}=8,623
\end{aligned}
$$

Kaidah pengujian:

Jika $\mathrm{t}$ hitung $\geq \mathrm{t}$ tabel, maka tolak Ho artinya signifikan.

Jika $\mathrm{t}$ hitung $\leq \mathrm{t}$ tabel, maka terima Ho artinya tidak signifikan.

Berdasarkan perhitungan di atas, $\alpha=0,05$ dan $\mathrm{n}=30$, uji satu pihak:

$\mathrm{dk}=\mathrm{n}-2=30-2=28$, sehingga diperoleh $\mathrm{t}$ tabel $=1,701$

Ternyata $\mathrm{t}$ hitung lebih besar dari $\mathrm{t}$ tabel atau $8,623>1,701$, maka Ho ditolak, artinya ada hubungan yang signifikan antara kemampuan membaca kritis terhadap kemampuan menulis argumentasi.
Kesimpulan, bahwa keberadaan kemampuan membaca kritis terhadap kemampuan menulis argumentasi tergolong adalah sangat kuat, artinya kemampuan membaca kritis sangat mendukung terhadap kemampuan menulis argumentasi.

\section{Simpulan}

Keberadaan kemampuan membaca kritis terhadap kemampuan menulis argumentasi tergolong adalah sangat kuat $(0,852)$, artinya kemampuan membaca kritis sangat mendukung terhadap keberadaan kemampuan menulis argumentasi. Di mana variabel kemampuan membaca kritis memberikan kontribusi terhadap variabel kemampuan menulis argumentasi sebesar $72,59 \%$, dan juga terlihat bahwa $t_{\text {hitung }}$ lebih besar dari $\mathrm{t}$ tabel atau $8,623>1,701$, artinya ada hubungan yang signifikan antara kemampuan membaca kritis terhadap kemampuan menulis argumentasi.

Diharapkan hasil penelitian ini dapat memberikan gambaran yang jelas mengenai hubungan antara kemampuan membaca kritis (X) dengan kemampuan menulis argumentasi (Y), sehingga nantinya dapat digunakan sebagai acuan dalam mengembangkan kegiatan pembelajaran bahasa Indonesia yang lebih unggul dan bermutu, baik itu dari pihak guru, sekolah, maupun pengelola pendidikan dan lembaga terkait lainnya.

\section{Daftar Pustaka}

Arikunto, Suharsemi. 1993. Dasar-Dasar Evaluasi Pendidikan. Jakarta: Bumi Aksara.

Bait, Urais dkk. 1987. Kemampuan Berbahasa Indonesia. Jakarta: Depdikbud.

Departemen Pendidikan Nasional. 2006. Panduan Pengembangan Silabus Mata Pelajaran Bahasa Indonesia Sekolah Menengah Pertama. Jakarta: Depdiknas.

Halim, Amran dkk. 1981. Kemampuan Berbahasa Indonesia Murid VI SD yang Berbahasa Bugis: Mendengarkan dan Berbicara. Jakarta: Depdikbud.

Keraf, Gorys. 1982. Argumentasi dan Narasi. Jakarta: Gramedia. 
Volume 1, Nomor 1, Januari 2019

ISSN 2655-3031 (P)

ISSN 2655-7851 (E)

Margono, S. 2005. Metode Penelitian Pendidikan. Jakarta: Rineka Cipta.

Nurhadi. 1987. Membaca Cepat dan Efektif. Bandung: Sinar Baru.

Nurgiyantoro, Burhan. 1987. Penilaian dalam Pengajaran Bahasa dan Sastra. Surabaya: Usaha Nasional.

Nurgiyantoro, Burhan. 1995. Penilaian dalam Pengajaran Bahasa Indonesia. Yogyakarta: BPFE.

Pusat Pembinaan dan Pengembangan Bahasa. 1988. Kamus Besar Bahasa Indonesia. Jakarta: Depdikbud.

Poerwadarminta. 1984. Kamus Umum Bahasa Indonesia. Jakarta: Balai Pustaka.

Purwanto, M. Ngalim. 1988. Prinsip-Prinsip dan Teknik Evaluasi Pengajaran. Bandung: Remaja Karya.
Pateda, Mansoer. 1989. Analisis Kesalahan. Flores: Nusa Indah.

Riduwan. 2009. Metode \& Teknik Menyusun Proposal Penelitian. Bandung: Alfabeta.

Semi, Atar. 1993. Rancangan Pengajaran Bahasa dan Sastra Indonesia. Bandung: Angkasa.

Suhartono. 2005. Dasar-Dasar Menulis Karangan. Bengkulu: FKIP Universitas Bengkulu.

Tarigan, H. G. 1979. Membaca Sebagai Suatu Keterampilan Berbahasa. Bandung: Angkasa.

Tarigan, H. G. 1993. Menyimak Sebagai Suatu Keterampilan Berbahasa. Bandung: Angkasa. 